\title{
MAMMOGRAPHY FOR BREAST CANCER SCREENING IN BRAZIL: A CURRENT PROFILE
}

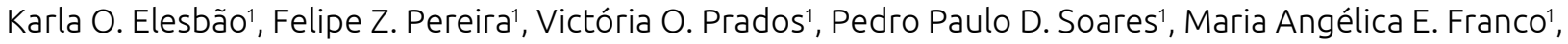
Fabiane A. Carvalho'

${ }^{1}$ Centro Universitário de Anápolis (UniEVANGÉLICA) - Anápolis (GO), Brazil.

Objectives: To quantify the number of bilateral screening mammographys performed for the first time in women over 40 years of age in Brazil, based on the variables educational status, previous clinical examination and age group. Methods: Ecological study, population-based and cross-sectional design. Considered the total number of bilateral screening mammographys performed in women over 40 years of age for the first time between 2009 and 2015. The data were collected from the Breast Cancer Information System (SISMAMA/SUS). Initially, descriptive statistics were performed and then the data were analyzed by ratio scale and relative frequency. Results: A total of 1,157,533 screening mammographys were performed during the quoted period, and in the years 2013 and 2014, there was a consecutive decrease of $37.7 \%$ and $51.6 \%$, respectively, in the total number of examinations. Regarding the educational status of the women who took the exam for the first time, $54.6 \%$ had incomplete elementary education, and $9.44 \%$ were illiterate. Of these, $43.6 \%$ and $53.7 \%$, respectively, had not had previous clinical examination of the breasts. Moreover, the analysis by age group shows that $26.5 \%$ of those who did not complete elementary school were between 40 and 44 years of age, and $16 \%$ of those with no schooling were 50 to 54 years old. Conclusion: This study verified that the decrease in the number of bilateral screening mammographys in the years 2013 and 2014 may be linked to the approval of Administrative Rule number 1.253/2013, which restricts the examination to women between 50 and 69 years of age. The low level of educational status, in turn, influenced in less demand of both the clinical examination and the screening test for cancer. The age group, however, differed from the Ministry of Health standard, which shows that women newly inserted into the risk group for screening tend to carry out preventive measures more frequently. Therefore, less restricted access to mammography is necessary, as well as health promotion measures that encourage lower- educated middle-aged women to take preventive measures with their health. In this way, it will be possible to identify breast lesions in the initial stages, to treat them and, consequently, to reduce the sequels generated by breast cancer. 